\title{
Tibiran - Jaunac
}

Grotte de Tibiran

\section{Michel Menu}

\section{(2) OpenEdition}

12 Journals

Édition électronique

URL : http://journals.openedition.org/adlfi/10599

ISSN : 2114-0502

Éditeur

Ministère de la culture

Référence électronique

Michel Menu, «Tibiran - Jaunac », ADLFI. Archéologie de la France - Informations [En ligne], Midi-

Pyrénées, mis en ligne le 01 mars 1997, consulté le 21 avril 2019. URL : http://

journals.openedition.org/adlfi/10599

Ce document a été généré automatiquement le 21 avril 2019.

(c) Ministère de la Culture et de la Communication, CNRS 


\title{
Tibiran - Jaunac
}

\author{
Grotte de Tibiran
}

\section{Michel Menu}

Date de l'opération : 1990 - 1991 (RE)

Inventeur(s) : Menu Michel

1 Sous la conduite d'A. Clot, M. Menu, P. Walter et G. Querre (LRMF, Paris) s'est effectuée en mars 1990 une première mission à Tibiran, séance assortie de six microprélèvements pariétaux (cf. supra Niaux). Une seconde reconnaissance eu lieu en novembre 1991 (un prélèvement), parallèlement aux travaux effectués dans la cavité voisine de Gargas ( $c f$. supra). Une problématique spécifique propre à ces deux grottes a été développée avec notamment l'étude comparative des peintures des empreintes «mutilées» de mains négatives ainsi que celle des figurations animales.

2 Comme pour Gargas, aucune charge n'a pu être observée au MEB : il s'agit donc également de simples pigments. En revanche, la peinture rouge utilisée à Tibiran (main $\mathrm{n}^{\circ} 10$, tâches rouges sur un pendant rocheux et sur le plancher calcifié) est différente de celle qui l'avoisine : il s'agit d'une ocre, variété d'argile comprenant $20 \%$ d'oxydes de fer et une proportion importante d'impuretés, principalement du phosphore. Le mode de dépôt est également différent du panneau principal de la Salle I de Gargas avec ici mise en évidence, malgré l'état moyen de conservation, d'une projection (à l'aide d'un tampon), comme l'attestent des gouttelettes caractéristiques (diamètre : $1 \mathrm{~mm}$ ).

3 Les figures animales sont aussi distinctes de celles de la Grotte Supérieure (cf. Gargas supra): la gravure de cheval a été rehaussée avec un «fusain» qui a laissé de gros morceaux de charbons de bois, technique faisant penser au Magdalénien moyen des Trois Frères ou de Fontanet. Le contour animal indéterminé de couleur noire (bouquetin ?) est, en revanche, fait d'un pigment de bioxyde de manganèse disposé en amas de cinq à dix micromètres et qui, selon les auteurs, pourrait alors être interprété comme une coloration naturelle de la paroi. 
INDEX

Index chronologique : Paléolithique supérieur

Index géographique : Midi-Pyrénées, Hautes-Pyrénées (65), Tibiran-Jaunac operation Relevé d'art rupestre (RE) 